\title{
Collections of the Swiss Institute for Children's and Youth Media and their Public Access
}

\author{
Roger Meyer
}

SIKJM

The Swiss Institute for Children's and Youth Media, Schweizerisches Institut für Kinder- und Jugendmedien (SIKJM), an associated institute of the University of Zurich and the Swiss section of IBBY (International Board on Books for Young People), accommodates the only documentation centre of Switzerland, which collects children's literature and secondary literature of a wide range, with historical and contemporary interest. The main activities of the institute are research and documentation in the field of children's and youth media and reading promotion. It cooperates with similar institutions in other European countries.

The library contains some 50,000 items and approximately three-quarter of these are primary media. The secondary literature comprises reference books, monographs and periodicals. The library consists of the cultural heritage of Swiss, German, and also international children's literature. Naturally the various collections have therefore a special focus on Swiss children's literature (children's literature by Swiss authors and children's books published by Swiss publishing houses or by Swiss editors). However, the collected books from the other German- speaking countries (Germany, Austria) from the major holding. Another substantially important part of collection with an international character is based on the works of authors and illustrators nominated biennially for the Hans Christian Andersen Award, and the International Board on Books for Young People (IBBY) Honour List. Since 1988, IBBY has donated one set of the books to the institute. Permanent collections of IBBY award books are housed at the International Youth Library in Munich, Bibiana Research Collection in Bratislava, Japanese national section of IBBY in Tokyo, and the Northwestern University Library at Evanston, Illinois.

Different projects have been developed in the last few years to enable a wider public, and more detailed insights into old and rare children's books, as well as to make it easier for the non-librarian to find the adequate secondary material. Keywords such as 'catalogue enrichment' and 'digitizing books' are included as the focus of these projects, which will be discussed below. 


\section{The Swiss Institute for Children's and Youth Media (SIKJM)}

SIKJM was established in January 2002, created through the merger of the Schweizerisches Jugendbuch-Institut (SJI, established in 1968) and the Schweizerischer Bund für Jugendliteratur (SBJ, established in 1954). The Johanna Spyri Foundation is the body responsible for SIKJM, and the Johanna Spyri Archive is incorporated into the Johanna Spyri Foundation. Headquartered in Zürich, SIKJM also has branches in the French- and Italian-speaking regions of Switzerland. It is supported by grants from the Swiss Federal Office of Culture and the State Secretariat for Education and Research.

SIKJM's research projects are concerned with historical research including the life and works of Johanna Spyri, and, among other things, new media, fantasy literature and the first steps taken by young children in the reading process. The results of research projects are published in various forms, such as books, contributions to conferences, exhibitions, e.g. in the monograph series Beiträge zur Kinder- und Jugendmedienforschung (published by SIKJM) or the online journal kids + media, a cooperative project of SIKJM and the Institute of Popular Culture Studies at the University of Zurich. SIKJM develops projects for promoting reading and implements them throughout Switzerland with the help of cantonal and regional organizations. At the moment, reading promotion focuses on projects for preschool and all school levels.

The range of services provided includes book and media recommendations, courses for university students and teacher training courses as well as conferences. Specialist magazines in German (Buch\&Maus), French (Parole) and Italian (Il Folletto) present background reports, interviews, and articles on the latest developments in the field of child and youth literature. The institute helps to find specialists for juries e.g. the Biennial of Illustration in Bratislava or the Hans Christian Andersen award. It also organizes exhibitions on outstanding personalities in the field of child and youth literature together with their work as well as on historical, current and artistic trends.

\section{History of the collections}

In 1968, Franz Caspar, founder of the institute, made a public appeal to leave children's books and books for young people to the new institute. This gesture was the starting point for the institute's work, which received old and new books from private individuals as well as from publishing houses. Due to the German-speaking publishers, it was possible to establish a representative collection over the years. Because there were no financial means at hand in order to buy primary literature, it was not possible to specifically plan the building of the collection. Therefore the library was at the beginning stocked by accident.

Following the foundation, the Schweizerisches Jugendbuch-Institut (SJI) had established itself rapidly as a centre of a group of enthusiastic collectors, including Bettina Hürlimann (1909-1983, Atlantis-Verlag, Zurich), Elisabeth Waldmann (1922-1996, bookseller, Zurich) and Peter Keckeis (1920-2007, publisher, Küsnacht). These three collectors left their rich private collections of children's books and books for young people to the institute. 


\section{Bettina Hürlimann-collection}

The origin of this collection can be compared to the biography of her owner. Bettina Hürlimann was born 1909 as the first child of the publisher Gustav Kiepenheuer in Weimar. At the age of 19 she entered her education as a typographer at the Academy of Graphic Arts and the Book Trade in Leipzig. In 1931 Bettina Kiepenheuer was employed by the Atlantis Verlag in Berlin and more and more she became the right hand of the director Martin Hürlimann, 1933 she became his wife and they had four children. The collection really developed - as she described herself - particularly on these familial grounds:

My children's book collection was the result of a library for the own use of a editor family with many children. When the children were still very young, the parents began to publish their own children's books especially picture books. The basis of my children's book collection was therefore a library compiled for my children and for the work of a publishing house, stocked with interesting picture books from all those countries we had access to, shortly before and after the second world war.

(Hürlimann 1977)

In her time, Bettina Hürlimann was recognized as one of the world's leading authorities on the subject of children's books and their illustration. She has been responsible for creating the international community of children's books. For instance, she was a founding member of IBBY and this resulted in a lot of friendships with internationally renowned authors and artists of children's books such as Astrid Lindgren, Pamela Lyndon Travers and many others (see below the inscription by Maurice Sendak to her).

More than 4,100 books are part of the collection, which the institute has housed since 1984. A catalogueue of the Hürlimanncollection was edited in 1992 by the institute. If one runs over the pages of this catalogueue it mirrors the personal literary and artistic interests of Bettina Hürlimann. On one hand, her main interest was illustration, and on the other hand, fantastic children's literature beginning from fairy tales to nonsense literature.

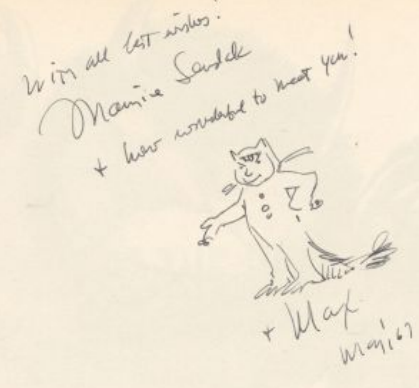

WHERE THE WIID THINGS ARE

Figure 1. Where the Wild Things Are by Maurice Sendak with a dedication from the author to Bettina Hürlimann from 1967

Other important parts of the collection focus on the development of the non-fiction books for children, on books around the "Struwwelpeter" topic, and especially the integrated collection of books called "Robinsonaden", variations of the original text Robinson Crusoe first written in 1719 by the Englishman Daniel Defoe. The title figure "Robinson" was Bettina's most beloved character 
as a young reader. The collection also has bibliophilic treasures such as the second edition of the Swiss Family Robinson by Johann David Wyss and his son Johann Rudolf Wyss, as well as an early English edition of Defoe's Robinson from 1783. Also of special interest in this subcollection is the role of the illustrations in the different editions.

Let's have a closer look at the fine collection of historic non-fiction books. There is an edition of Johann Amos Comenius' Orbis sensualium pictus [The Visible World in Pictures] of 1746, as well as the textbook Janua linguarum reserata aurea [The Door of Languages Unlocked] (1805). A very special variation from the baroque era is Orbis terrarum in nuce [The World in a Nutshell] published in Vienna in 1722. An other highlight is the Elementarwerk [Elementary Book], by Johann Bernhard Basedow (1774) - a complete edition with all plates - with the drawings of Daniel Chodowiecki.

A totally different 'world' of books can be met in the genre of fantastic children's literature and fairy tales. The first editions of Kinder-and Hausmärchen of the brothers Grimm (1812) and Achim von Arnim and Clemens Brentano's collected children's songs Des Knaben Wunderhorn represent shining stars of the Hürlimann-collection as well as the American first edition of Lewis Caroll's Alice in Wonderland.

It was Bettina Hürlimann wish that her library would be used after her death by both students and bibliophiles. Therefore she left her collected books and original drawings to the institute. After the collection was catalogueued and published by means of her daughter Regine Schindler between 1983 and 1992, an in-house, re-catalogueuing project started in 2011 in order to make the data online available in the online public access catalogueue of NEBIS (Network of Libraries and Information Centres in Switzerland). Another project, which will be described in detail below, is the digitalization of volumes in the collection in the so called 'e-rara-project', discussed later in this essay.

\section{Elisabeth Waldmann-collection}

Elisabeth Waldmann (1922-1996) was a bookseller who lived in Zurich. She was also part of the Historic Children's Book Society in Zurich, like Bettina Hürlimann, and Peter Keckeis (discussed below). Waldmann's interest in children's literature was more pedagogically orientated. She was always in touch with teachers of all school levels, whom she both advised and got inspiration and information from their daily work with children. Her international children's books section in the bookshop on famous Bahnhofstrasse in Zurich was a meeting point and information centre for all teachers and librarians. She always kept one copy for her own library and former clients gave her their libraries as well.

The personal relationship to a book on the basis of the friendship with the author was always very important to Elisabeth Waldmann. Therefore her library houses a lot of written dedications of artists in books. Among her closest friends were the German illustrator Binette Schroeder, and the 
American writers-illustrators, Maurice Sendak and Ezra Jack Keats. Picture books produced in the USA very well represented in the collection.

Besides the friends Waldmann had among the illustrators, she also had a close friend in Susan Hirschman, the respected founder and publisher of Greenwillow Books.

With her husband Richard, Elisabeth shared an interest in fairy tales. Besides her collection of fairy tale illustrations throughout the $19^{\text {th }}$ century, she also owned a large collection of Red Riding HoodBooks. In 2002 this collection was given to the Bilderbuchmuseum in Troisdorf, Germany, because at that time there was neither enough place nor the personal resources in order to treat the collection at the institute. However, after the heirs of the collection decided to leave the 9,000 books to the institute, it was united with the collection of Bettina Hürlimann.

\section{Peter Keckeis-Collection}

The publisher Peter Keckeis (1920-2007) was a passionate collector like Hürlimann and Waldmann. Keckeis was also head of diverse Swiss publishing companies (Benziger Verlag, Einsiedeln and Zurich, Huber Verlag, Frauenfeld). Because he was collecting historic Swiss children's literature, he also supported firmly the project of the annotated bibliography about Swiss children's literature published between 1750 and 1900, which was realized in 1993. Keckeis collected around 400 children's books and books for young people published before 1900. His collection contains next to popular works from the famous German author Christoph von Schmid, that have probably been sold in Swiss publishing houses as pirate copies, rarities like a reading primer in French, edited in Lausanne in 1789 or a copy of a rare French Le Robinson Suisse by Johann David Wyss, illustrated by Télory, published

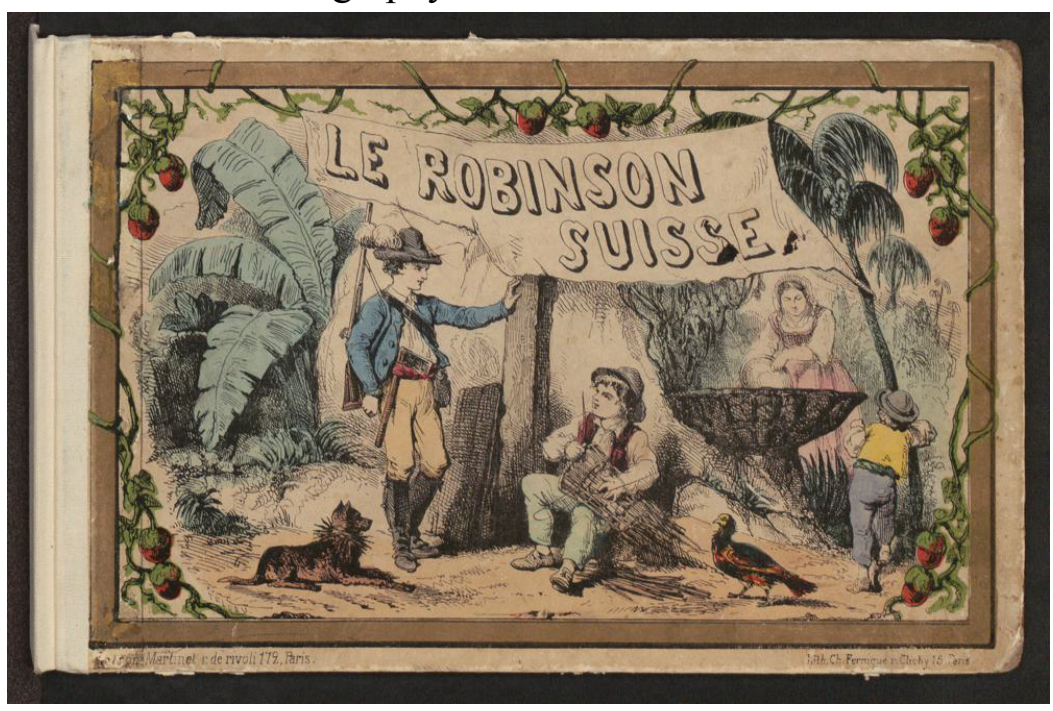

Figure 2. Rare French edition of the Swiss Family Robinson (Le Robinson Suisse) by Johann David Wyss, illustrated by Télory (circa1850) in Paris around 1850.

The Keckeis collection provides material for research on children's literature and on children and youth culture of the $18^{\text {th }}$ and $19^{\text {th }}$ century in general, mainly in German and French speaking Switzerland.

\section{Online Access to the Collections: NEBIS Catalogue and e-rara.ch}

Considering, that there is a special interest group in children's literature, an institution like SIKJM should be ready and willing to open as much as possible an insight into the rare collections of the 
library. In the past, there was always the option to show particular rarities in exhibitions. The problem was that this meant always an enormous amount of resources and space. Online access facilities are therefore much more efficient and timely.

Two options are on hand: one is the institute's official website and the other are databases which incorporate records and library holdings. In the following discussion the focus is firstly on the NEBIS catalogue and its catalogue enrichment possibilities, and secondly, on a Swiss internet platform of a nation wide project making digitized rare books in full text accessible.

\section{NEBIS catalogue}

The Network $^{1}$ of Libraries and Information Centres in Switzerland (NEBIS) comprises over 80 university, technical college and research institute libraries from all language regions. NEBIS is a member of the Informationsverbund Deutschschweiz IDS ${ }^{2}$. The NEBIS catalogue contains about 4.2 million titles, including books, serials, journals and non-book materials. The SIKJM library, with currently over 36,700 records, has been part of the NEBIS-Verbund since its very beginning in 1999. At the same time, the integrated library system Aleph, which is in use worldwide in academic, research, and national libraries was implemented. The software enables editing library data of a heterogenous background, so it can be used as an instrument to catalogue library materials and also documents like newspaper articles or other pamphlets. This allows the library staff and the users to follow the research been done at the time.

In a cooperative digitization project of SIKJM and the ETH-Bibliothek (Library of the Swiss Federal Institute of Technology) in 2008, the covers and tables of contents of each volume of the secondary literature were digitized and Optical Character Recognition (OCR) captured and attached to the respective catalogue record. With this additional access it is easier to identify suitable material the user is looking for, and it means a valid saving of time.

Another part of the project was the enrichment of the library catalogue with scanned posters, original illustrations and photographs from the collections of the institute. Therefore the content has been digitized and for the presentation in the NEBIS provided. The main library of the Swiss Federal Institute of Technology Zurich, ETH-Bibliothek, contributed existing digitisation knowhow and the necessary infrastructure such as several state of the art book scanners. The content selection, allocation as well as post-processing of the materials were managed by SIKJM.

The catalogue enrichment enabled the online presentation with visual components to give a broader insight into the institute's materials. A very important part is the photo collection of the Johanna Spyri Archive, which is part of SIKJM. 
Since its foundation, the Spyri-Archive has been part of the institute. The archive gathers research material about the world famous children's books writer and her book Heidi (1880) from all over the world, including many noted studies as well as unpublished research results concerning various aspects of her life and work, especially the reception history. Various original documents describe the history of the world reception and also the life of the author is well documented. Part of the archive includes original photographs of Spyri and her close relatives. These photographs are also integrated as part of the catalogue enrichment in the NEBIS catalogue. In the past, different exhibitions presented personal material of Spyri belonging to the institute, among them the original writing desk, and a porcelain tea cup donated to Spyri by the close friend of the family, Richard Wagner (1813-1883), the world famous german composer, who was living in the same building in Zurich. In 2011 SIKJM handed over more than 1,000 documents on deposit to the Central Library of Zurich. These include numerous letters, manuscripts, notes and documents of Johanna Spyri, their families and from their friends.

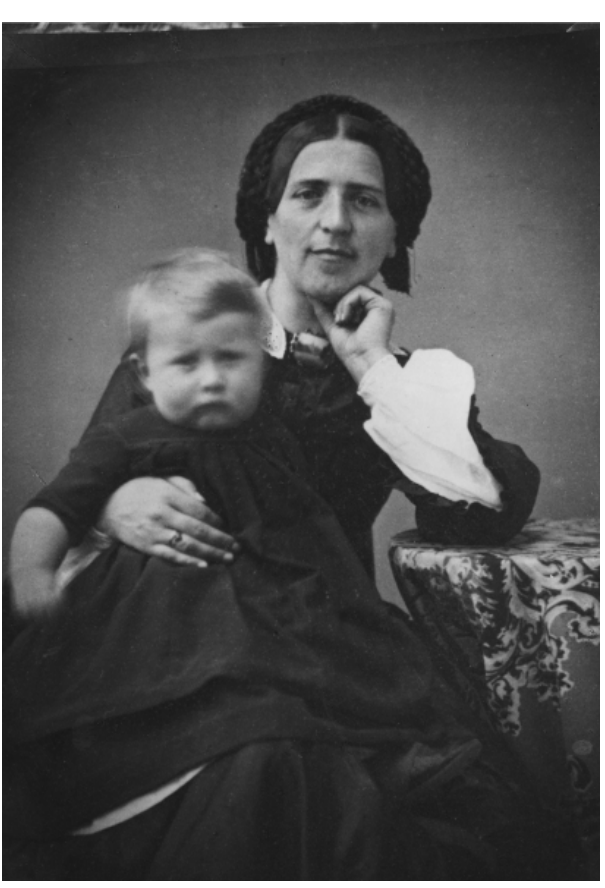

Figure 3. World famous author Johanna Spyri (1827-1901) with her son

In addition to a nearly complete collection of first editions of Spyri's works, the archive holds a wide selection of Heidi books published in more than 50 countries and translated in over 30 languages. The catalogue enrichment is, according to the financial and personal ressources, a project that should be enlarged in future and therefore is not finished.

\section{e-rara.ch}

e-rara.ch is a national collaborative project forming part of the Swiss innovation and cooperation programme e-lib.ch: Swiss Electronic library ${ }^{3}$. The project is run by the Bibliothèque de Genève ${ }^{4}$, the ETH-Bibliothek Zurich ${ }^{5}$, the University Library of Basel ${ }^{6}$, the University Library of Bern ${ }^{7}$, and Zurich Central Library ${ }^{8}$. The e-rara.ch platform makes digitized rare books from Swiss libraries available to the public, free of charge. Other Swiss libraries ${ }^{9}$ participating in the project are: the BPU Neuchâtel ${ }^{10}$, the Bibliothèque des Pasteurs ${ }^{11}$, the BCU Lausanne ${ }^{12}$, the BCU Fribourg ${ }^{13}$, the Foundation of the Works of C.G.Jung ${ }^{14}$, Zürich and the Biblioteca Salita dei Frati ${ }^{15}$, Lugano. The present selection of Swiss children's books and books for young people provides material for research on children's literature and on children and youth culture of the $18^{\text {th }}$ and $19^{\text {th }}$ century in general, mainly in German and French speaking Switzerland. Most of the selected volumes are part of the private collection Keckeis, which has been mentioned above.

The e-rara platform now allows the public to read rare historic books of value, without leaving home and not doing any harm to precious items. The digitized prints, in high resolution colour, can be easily read on the screen thanks to its structure; they are also downloadable. The following 
functions are available to the user: image navigation with a number of different viewing modes (scrolling, zoom function, miniature view), structural metadata as a navigation aid ("virtual table of contents"), browsing in collections by author, title, year of publication, and so on, different search functions and free PDF download of complete books or individual chapters. It is also possible to gain access to these books by searching the NEBIS catalogue.

\section{Conclusion}

Being the Swiss competence centre for children's and youth media, it is a vital element of public relation to open the doors to the treasure chest of the library. In order to present the Johanna Spyri Archive, the various internationally renowned collections of book experts and lovers like Bettina Hürlimann, the special interest collection of reference literature in the field and historic rarities SIKJM uses technically advanced facilities in order to give new insights to the public and the scientific world into the world of books for children and young people.

\section{Endnotes}

${ }^{1} \mathrm{http}: / /$ www.nebis.ch/verbund/nebis_karte_e.pdf

${ }^{2} \mathrm{http}: / /$ www.informationsverbund.ch/

${ }^{3} \mathrm{http}: / /$ www.e-lib.ch/

${ }^{4} \mathrm{http}: / /$ www.ville-ge.ch/bge

${ }^{5}$ http://www.library.ethz.ch

${ }^{6}$ http://www.ub.unibas.ch/

${ }^{7}$ http://www.ub.unibe.ch/

${ }^{8}$ http://www.zb.uzh.ch/

${ }^{9} \mathrm{http}: / /$ www.e-rara.ch/doc/page/adjunctLibraries

${ }^{10} \mathrm{http}: / /$ bpun.unine.ch/

${ }^{11} \mathrm{http}: / /$ www2.unine.ch/bibliotheque/page23128.html

${ }^{12} \mathrm{http}: / /$ www.unil.ch/bcu/

${ }^{13} \mathrm{http}: / / \mathrm{www} . f r . c h /$ bcuf/

${ }^{14} \mathrm{http}: / /$ www.cgjung-werke.org

${ }^{15} \mathrm{http} / / /$ www.bibliotecafratilugano.ch 


\section{Reference}

Hürlimann, Bettina (1977) Seven Houses: My Life with Books. New York: Crowell.

\section{SOCR}

\section{Biographical Note}

Roger Meyer is academic librarian, and head of the SIKJM-library. He is a reviewer and columnist for the journal Buch \& Maus. His main interest is the representation of Africa and Africans in media for children and young people. www.sikjm.ch 